\title{
Lack of Galanin 3 Receptor Aggravates Murine Autoimmune Arthritis
}

\author{
Bálint Botz $^{1}$ - Ágnes Kemény ${ }^{1} \cdot$ Susanne M. Brunner $^{3} \cdot$ Felix Sternberg $^{3}$. \\ Janka Csepregi $^{4}$ - Attila Mócsai ${ }^{4}$ - Erika Pintér ${ }^{1}$ • Jason J. McDougall ${ }^{5}$. \\ Barbara Kofler ${ }^{3}$ - Zsuzsanna Helyes ${ }^{1,2}$
}

Received: 23 November 2015 / Accepted: 18 February 2016/Published online: 3 March 2016

(C) The Author(s) 2016. This article is published with open access at Springerlink.com

\begin{abstract}
Neurogenic inflammation mediated by peptidergic sensory nerves has a crucial impact on the pathogenesis of various joint diseases. Galanin is a regulatory sensory neuropeptide, which has been shown to attenuate neurogenic inflammation, modulate neutrophil activation, and be involved in the development of adjuvant arthritis, but our current understanding about its targets and physiological importance is incomplete. Among the receptors of galanin $\left(\mathrm{GAL}_{1}{ }_{3}\right), \mathrm{GAL}_{3}$ has been found to be the most abundantly expressed in the vasculature and on the surface of some immune cells. However, since there are minimal in vivo data on the role of $\mathrm{GAL}_{3}$ in joint diseases, we analyzed its involvement in different inflammatory mechanisms of the $\mathrm{K} / \mathrm{BxN}$ serum transfermodel of autoimmune arthritis employing $G A L_{3}$ genedeficient mice. After arthritis induction, $\mathrm{GAL}_{3}$ knockouts demonstrated increased clinical disease severity and earlier
\end{abstract}

Barbara Kofler

b.kofler@salk.at

1 Molecular Pharmacology Research Team, Neuroscience Centre and János Szentágothai Research Centre, Department of Pharmacology and Pharmacotherapy, Medical School, University of Pécs, Pécs, Hungary

2 MTA-PTE NAP B Chronic Pain Research Group, Pécs, Hungary

3 Laura Bassi Centre of Expertise-THERAPEP, Research Program for Receptor Biochemistry and Tumor Metabolism, Department of Pediatrics, Paracelsus Medical University, Muellner Hauptstr. 48, 5020 Salzburg, Austria

4 Department of Physiology, Semmelweis University School of Medicine and MTA-SE „Lendület” Inflammation Physiology Research Group, Budapest, Hungary

5 Departments of Pharmacology and Anesthesia, Pain Management \& Perioperative Medicine, Dalhousie University, Halifax, NS, Canada hindlimb edema than wild types. Vascular hyperpermeability determined by in vivo fluorescence imaging was also elevated compared to the wild-type controls. However, neutrophil accumulation detected by in vivo luminescence imaging or arthritic mechanical hyperalgesia was not altered by the lack of the $\mathrm{GAL}_{3}$ receptor. Our findings suggest that $\mathrm{GAL}_{3}$ has antiinflammatory properties in joints by inhibiting vascular hyperpermeability and consequent edema formation.

Keywords Neuropeptide · Galanin · Inflammation · Arthritis $\cdot$ Plasma leakage $\cdot$ Myeloperoxidase

\section{Introduction}

Rheumatoid arthritis (RA) is a chronic, inflammatory autoimmune disease that primarily affects the synovial joints manifesting as pain, stiffness, and synovitis. Edema formation and tenderness around the affected joints are characteristics of the early phase of the disease which is associated with progressive, irreversible degeneration and bone remodeling in later stages. Despite the increasing number of novel drugs introduced to treat RA (Smolen et al. 2007), long-term therapeutic relief is still poor for most patients (Jones et al. 2003). As such, there is still a great need for the identification of novel targets and the subsequent development of efficacious and safe drugs.

While immunological aspects of the pathological mechanisms of RA have been well described, components of the nervous system have long been believed to be potential contributors to immune-mediated disease conditions and recent evidence has corroborated this assertion (Levine et al. 1985; Bozic et al. 1996; Brogden et al. 2005; Kioussis and Pachnis 2009). The activation of the sensory nervous system triggers the peripheral release of several peptide and non-peptide mediators. These can have both anti- or proinflammatory effects, 
thereby regulating the inflammatory microenvironment by altering blood flow, vascular permeability, and leukocyte activity. This process, known as neurogenic inflammation (Holzer 1998), has been described clinically, where damage to the central or peripheral nervous system can dramatically alter the course of inflammatory diseases, such as RA (Thompson and Bywaters 1962; Kim et al. 2012). It has also been shown in preclinical models that an intact innervation is necessary for the development of joint inflammation, suggesting a pivotal role of pro-inflammatory neurotransmitters (McDougall et al. 1999; Kane et al. 2005; Stangenberg et al. 2014). In contrast, however, the defunctionalization of peptidergic sensory afferents can also lead to increased inflammation in several animal models (Helyes et al. 2004; Borbely et al. 2015). Thus, the role of neurogenically released peptide mediators in joints can be somewhat divergent with some neuropeptides being clearly pro-inflammatory (e.g., substance P) (McDougall et al. 1994), while others have anti-inflammatory properties (e.g., pituitary adenylate cyclase-activating polypeptide or endomorphin-1) (McDougall et al. 2004; Botz et al. 2014). The role of numerous other peptide mediators and their receptors including the galanin family in RA has yet to be examined.

Galanin is a sensory neuropeptide with a length of 30 (29 in rodents) amino acids that is ubiquitously expressed in both the central and peripheral nervous systems and has numerous biological and physiological functions. Three galanin receptors $\left(\mathrm{GAL}_{1-3}\right)$ have been identified, which are all G-proteincoupled receptors (GPCR) showing distinct differences regarding their tissue expression pattern (Lang et al. 2015). Both $\mathrm{GAL}_{1}$ and $\mathrm{GAL}_{2}$ are present in abundance throughout the central nervous system, whereas $\mathrm{GAL}_{3}$ expression is much more restricted to the hippocampus (Mennicken et al. 2002). In non-neural tissues, $\mathrm{GAL}_{2}$ and $\mathrm{GAL}_{3}$ are predominantly expressed (Santic et al. 2007). The functional coupling and signal transduction pathways of the three galanin receptors are substantially different, giving rise to the great variety of galanin-mediated effects. While it was shown that $\mathrm{GAL}_{1}$ mainly signals via $G_{i / 0}$-type $G$ proteins and $\mathrm{GAL}_{2}$-mediated effects involve multiple classes of $\mathrm{G}$ proteins, the signaling pathways of $\mathrm{GAL}_{3}$ are not well understood (Lang et al. 2015). Galanin has been shown to be upregulated following nerve damage (Ch'ng et al. 1985; Skofitsch and Jacobowitz 1985; Hokfelt et al. 1987) and has been implicated in nociception (Liu and Hokfelt 2002; Lang et al. 2015), as both galanin and its receptors are expressed in dorsal root ganglia and in the spinal dorsal horn (Landry et al. 2005). Galanin knockout mice exhibit increased sensitivity to mechanical and thermal stimuli, whereas galanin-overexpressing mice show an increased thermonociceptive threshold (Blakeman et al. 2001; Holmes et al. 2003). Furthermore, the galanin peptide family is undoubtedly involved in the regulation of inflammatory processes with the galanin system being upregulated in the central and peripheral nervous systems in response to inflammation (Ji et al. 1995). Galanin has been shown to have anti-inflammatory and most importantly anti-edema effects in animal models of inflammation (Lang and Kofler 2011). $\mathrm{GAL}_{3}$ was found to be active in the dermal microvasculature, as treatment with its selective small molecule antagonist SNAP 37889 dose-dependently blocked the anti-edema effect of galanin (Schmidhuber et al. 2009). Furthermore, galanin gene-deficient mice lack neurogenic inflammatory responses and have impaired neutrophil recruitment into inflamed tissues (Schmidhuber et al. 2008). According to recent data, $\mathrm{GAL}_{2}$ but not $\mathrm{GAL}_{1}$ is expressed on both human and murine neutrophils, whereas galanin and $\mathrm{GAL}_{3}$ are expressed on murine neutrophils only. Additionally, it has been reported that galanin can act as a modulator of cytokine-induced neutrophil activation (Locker et al. 2015). Galanin itself has been implicated in arthritis as an endogenous regulatory mediator. Several studies reported a change in galanin mRNA levels, galanin-like immunoreactivity, and galanin peptide levels, respectively, in the rat dorsal horn of the spinal cord, dorsal root ganglia, and joint tissue after experimentally induced adjuvant arthritis (Hope et al. 1994; Calza et al. 1998; Calza et al. 2000; Qinyang et al. 2004). Hence, the galanin system poses a novel target for alternative treatment stategies for RA; however, no studies have been conducted identifying the relevant galanin receptor subtype.

The $\mathrm{K} / \mathrm{BxN}$ serum-transfer model of autoimmune arthritis (Kouskoff et al. 1996; Korganow et al. 1999) mimics numerous aspects of RA in humans. The model produces a transient, but profuse polyarthritis following systemic administration of exogenous antibodies (anti-glucose phosphate isomerase) with the involvement of neutrophils (but not of T/B cells). This arthritis model also has a distinct neurogenic component (Korganow et al. 1999; Botz et al. 2014; Stangenberg et al. 2014; Borbely et al. 2015).

Since galanin participates in the pathogenesis of arthritis and because $\mathrm{GAL}_{3}$ is expressed on murine neutrophils and has been shown to influence vascular components of inflammatory processes, we hypothesize that $\mathrm{GAL}_{3}$ is involved in inflammatory joint diseases. Therefore, the aim of the present study was to elucidate if $\mathrm{GAL}_{3}$ plays a role in the $\mathrm{K} / \mathrm{BxN}$ serum transfer model of autoimmune arthritis.

\section{Materials and Methods}

\section{Experimental Animals}

Experiments were conducted using 12-14-week-old male $G A L_{3}$ gene-deficient $\left(\mathrm{GAL}_{3}{ }^{--}\right)$mice and age-matched wildtype $\left(\mathrm{GAL}_{3}{ }^{++}\right)$controls (body weight $\left.25-30 \mathrm{~g}\right)$. $\mathrm{GAL}_{3}{ }^{-/-}$ (LEXKO-230) mice were obtained from the European Mouse Mutant Archive. The mice were generated by homologous recombination with targeting both coding exons. The 
mouse line was backcrossed onto a C57BL/6 lineage for at least seven additional generations and was maintained on this background. The successful knockout of the $G A L_{3}$ gene has been established recently (Brunner et al. 2014). All animals were $\mathrm{GAL}_{3}$ genotyped before the experiments. Animals were bred and kept in the Laboratory Animal House of the Department of Pharmacology and Pharmacotherapy of the University of Pécs, at $24-25{ }^{\circ} \mathrm{C}$ ambient temperature, and provided with standard rodent chow and water ad libitum under 12-h light-dark cycles.

\section{The K/BxN Serum-Transfer Induced Inflammatory Arthritis}

$\mathrm{K} / \mathrm{BxN}$ mice express a transgenic $\mathrm{T}$ cell receptor and the $\mathrm{MHC}$ class II allele $\mathrm{A}^{\mathrm{g} 7}$. This leads to the production of autoantibodies against the enzyme glucose-6-phosphate isomerase and consequent development of progressive polyarthritis. Transfer of $\mathrm{K} / \mathrm{BxN}$ serum into mice elicits a robust, albeit transient, polyarthritis. This serum transfer model mimics predominantly the effector phase of RA and depends mainly on mast cells and neutrophils, but not on lymphocytes (Monach et al. 2008). The sera of transgene-positive $(\mathrm{K} / \mathrm{BxN})$ and negative $(\mathrm{BxN})$ mice were harvested, pooled, and stored at $-80^{\circ} \mathrm{C}$ as described earlier (Korganow et al. 1999; Jakus et al. 2009). Arthritis was induced by a single intraperitoneal (i.p.) injection of $300 \mu$ of the arthritogenic $(\mathrm{K} / \mathrm{BxN})$ or control $(\mathrm{BxN})$ serum.

\section{Evaluation of Disease Severity and Hindpaw Edema}

Arthritis severity was evaluated daily until 13 days post serum injection by semiquantitative scoring between 0 and 10 based on two key signs of inflammation: edema and hyperemia. A score of $\leq 0.5$ represented a normal hindlimb, and 10 refers to the most severe level of joint inflammation with accompanying gait abnormality. Hindlimb edema was also monitored repeatedly (on days $0,2,4,6,8$, and 11 post serum injection) by plethysmometry (Ugo Basile, Comerio, Italy).

\section{Assessment of Mechanonociception and Joint Function}

The mechanical hyperalgesia of the hindpaw was measured every second day by dynamic plantar esthesiometry (Ugo Basile). Mechanonociceptive threshold was expressed as percentage of pretreatment controls. Grasping ability was tested repeatedly (on days $0,2,4$, and 6 post serum injection) by placing the mice on a horizontal wire-grid, which was then turned over and maintained in this position for $30 \mathrm{~s}$ or until the animal fell (Jakus et al. 2009).

\section{In vivo Fluorescence Imaging of Plasma Leakage}

On days 0,1 , and 5 , post serum injection mice received a retroorbital injection of the fluorescence contrast agent indocyanine-green $(0.5 \mathrm{mg} / \mathrm{kg}$ body weight $)$ dissolved in $5 \% w / v$ Kolliphor HS 15 solution (Sigma-Aldrich) (Kirchherr et al. 2009) under ketamine-xylazine anesthesia (ketamine $100 \mathrm{mg} / \mathrm{kg}$; xylazine $5 \mathrm{mg} / \mathrm{kg}$ body weight i.p.). It has been demonstrated that this micellar fluorescent contrast agent enables sensitive noninvasive detection of microvascular extravasation (Botz et al. 2014). The underlying principle of this technique is that the labeled micelles serve as nanoprobes that can leave the microvasculature of inflamed tissues, but not the intact vessels due to their size $(\sim 10 \mathrm{~nm})$. This results in retention and buildup of fluorophore in the inflamed tissue, culminating in increased fluorescence that correlates with the severity of the disease (Kenne and Lindbom 2011). Animals were imaged 20 min post-injection using the IVIS Lumina II system (Perkin-Elmer, Waltham, MA, USA). Imaging parameters were set to the following: auto acquisition time, $\mathrm{F} / \mathrm{Stop}=1$, Binning $=2$. The excitation and emission filters were $745 / 800 \mathrm{~nm}$. Data were analyzed using the Living Image ${ }^{\circledR}$ software; regions of interests (ROIs) were drawn around the hind limbs. A calibrated unit of fluorescence, the radiant efficiency ([photons $\left./ \mathrm{s} / \mathrm{cm}^{2} / \mathrm{sr}\right] /$ $\left[\mu \mathrm{W} / \mathrm{cm}^{2}\right]$ ) originating from the ROIs was used for further analysis.

\section{In vivo Bioluminescence Imaging of Neutrophil Myeloperoxidase Activity}

Luminol (5-amino-2,3-dihydro-1,4-phthalazine-dione) is a chemiluminescent reactive oxygen species sensor, which in vivo requires both the superoxide-production of nicotinamide adenine dinucleotide phosphate oxidase and the activity of the myeloperoxidase (MPO) enzyme. The MPO-dependent nature of luminol makes it a suitable chemiluminescent tracer to image the activity of this enzyme, and thereby the functioning of neutrophils in vivo, as most of the MPO-activity is localized in the phagosomes of those cells during inflammation (Gross et al. 2009; Tseng and Kung 2012). On days 0, 1, and 5, post serum injection mice received an i.p. injection of $20 \mathrm{mg} / \mathrm{ml}$ PBS-based solution of sodium-luminol (SigmaAldrich) at a dose of $150 \mathrm{mg} / \mathrm{kg}$, and were imaged $10 \mathrm{~min}$ post-injection using the IVIS Lumina II. Acquisition time was $60 \mathrm{~s}, \mathrm{~F} / \mathrm{stop}=1$, Binning $=8$. ROIs were applied as previously described and luminescence was expressed as total radiance (total photon flux/s).

\section{Histology}

Joint samples were harvested on day 14 following euthanasia by sodium pentobarbital (100 mg/kg i.p.). Ankle 
joints were fixed in $40 \mathrm{mg} / \mathrm{ml}$ buffered formaldehyde, dehydrated using ethanol and xylol, and finally decalcified with EDTA. The samples were embedded in paraffin, sectioned $(3-5 \mu \mathrm{m})$, and stained with fast green and safranine $\mathrm{O}$.

\section{Dynamic Mass Redistribution Assay}

Murine polymorphonuclear neutrophils were isolated from the bone marrow as described previously (Locker et al. 2015). Cells were resuspended in Hank's Balanced Salt Solution containing magnesium and calcium [HBSS $(+/+)]$ (Gibco), diluted in HBSS $(+/+)$ containing $20 \mathrm{mM}$ HEPES (Gibco), and then seeded onto EnSpire LFC-384 well plates coated with fibronectin (Perkin-Elmer) at a density to achieve a confluent monolayer $(60,000-80$, 000 cells/well). The plates were centrifuged for $10 \mathrm{~s}$ at $1000 \mathrm{~g}$ and equilibrated for $1 \mathrm{~h}$ in the EnSpire machine (Perkin-Elmer). First, the pretreatment baseline was acquired by measuring 4 repeats $(30 \mathrm{~s}$ each) followed by the addition of compounds [KC (the murine homolog of IL-8) $(1 \mathrm{pM}-100 \mathrm{nM}), \mathrm{KC}(1 \mathrm{pM}-100 \mathrm{nM})$ with $10 \mu \mathrm{M}$ galanin, $\mathrm{KC}(1 \mathrm{pM}-100 \mathrm{nM})$ with $1 \mu \mathrm{M}$ galanin, and $\mathrm{KC}$ $(1 \mathrm{pM}-100 \mathrm{nM})$ with $0.1 \mu \mathrm{M}$ galanin]. The plate was measured for 20 repeats. Each experiment was carried out in triplicate, and the mean was used to generate the dynamic mass redistribution (DMR) traces. The half maximal effective concentration $\left(\mathrm{EC}_{50}\right)$ of $\mathrm{KC}$ was then calculated.

\section{Expression Analysis}

Expression profiles of galanin and its receptors was performed in 16-24-week-old male $\mathrm{GAL}_{3}{ }^{-1-}$ and $\mathrm{GAL}_{3}{ }^{+/+}$mice as described previously (Brunner et al. 2014). Briefly, mice were euthanized by $\mathrm{CO}_{2}$ overdose and cervical dislocation. Tissue was dissected and immediately snap-frozen in liquid nitrogen. RNA isolation was performed with TRI Reagent (Molecular Research Center, Inc.) according to the manufacturer's instructions. Synthesis of cDNA was performed by use of random hexamer primers and Maxima reverse transcriptase (Thermo Scientific) according to the manufacturer's instructions. Expression profiles of galanin and $\mathrm{GAL}_{1-3}$ were quantified by quantitative real-time PCR using B-R SYBR Green SuperMix for iQ (Quanta BioSciences, Inc.) and iCycler iQ real-time PCR detection system (Bio-Rad Laboratories). Primer sequences and cycling conditions are taken from Brunner et al. (2014).

\section{Statistical Analysis}

Results are expressed as mean \pm SEM. Statistical evaluation was performed by Graphpad Prism ${ }^{\circledR}$. Functional data were analyzed by two-way ANOVA + Tukey's multiple comparison test, grasping ability results by logrank test, imaging, DMR assay, and expression analysis results by Student's unpaired $t$ test. $p$ values below 0.05 were considered significant.

\section{Results}

More Severe Arthritis Progression and Accelerated Edema Formation in $\mathrm{GAL}_{3}{ }^{-/-}$Mice Joint inflammation occurred in $\mathrm{GAL}_{3}{ }^{+/+}$and $\mathrm{GAL}_{3}^{--/}$mice with similar kinetics and peaks at day 7 , but $\mathrm{GAL}_{3}{ }^{-/-}$mice showed a more severe arthritis phenotype compared to wild types (peak difference observed from day 3 to 5 with $p<0.0001$ ) (Fig. 1a). The plethysmometric determination of the hindpaw volume revealed an earlier peak of edema formation in $\mathrm{GAL}_{3}{ }^{-1-}$ mice $\left(\mathrm{GAL}_{3}{ }^{-1-}\right.$ day 4 at $65 \%$; $\mathrm{GAL}_{3}{ }^{+/+}$day 6 at $50 \%$ ), and a more robust plasma extravasation on days 2 to 6 in $\mathrm{GAL}_{3}{ }^{-1-}$ mice compared to $\mathrm{GAL}_{3}{ }^{+/+}$wild types (peak differences on day 4 $p<0.0001$ and day $6 p=0.0238$ ) (Fig. 1b).

$\mathrm{GAL}_{3}$ Deficiency Does not Influence Nociception or Motor Performance in the Arthritis Model As RA is known to affect nociception and motor performance, we tested whether $\mathrm{GAL}_{3}$ is involved in pain perception. A considerable and similar mechanonociceptive threshold drop of about $40-50 \%$ was observed in both the $\mathrm{GAL}_{3}{ }^{-/-}$and $\mathrm{GAL}_{3}{ }^{+/+}$mice on day 8 of the experiment (Fig. 1c), indicating increased pain in both groups. Grasping ability also decreased steadily following serum injection. This reached a peak by day 6 as almost all $\mathrm{K} /$ BxN serum-treated $\mathrm{GAL}_{3}{ }^{-/-}$and $\mathrm{GAL}_{3}{ }^{+/+}$animals became unable to maintain their position on the grid for the duration of the test period (Fig. 1d).

Increased Early-Phase Arthritic Vascular Hyperpermeability in $\mathbf{G A L}_{3}$ Knockouts Plasma leakage after arthritis induction was assessed by in vivo fluorescence imaging. Pretreatment control fluorescence was comparable in $\mathrm{GAL}_{3}{ }^{-/-}$and $\mathrm{GAL}_{3}^{+/+}$mice. The degree of plasma extravasation increased sharply upon $\mathrm{K} / \mathrm{BxN}$ serum transfer in both groups, peaking $24 \mathrm{~h}$ after arthritis induction in the hyperacute phase of the disease. $\mathrm{GAL}_{3}{ }^{-1-}$ mice exhibited $40 \%$ greater vascular hyperpermeability $(p<0.01)$ compared to wild types. This significant difference in plasma leakage resolved by day 5 , albeit the overall degree of vessel hyperpermeability remained similar in the two groups (Fig. 2a, b).

Similar MPO-Activity and Joint Damage in Arthritic $\mathbf{G A L}_{3}{ }^{-1-}$ Mice As neutrophil recruitment is a characteristic of the $\mathrm{K} / \mathrm{BxN}$ model of autoimmune arthritis, we aimed to evaluate the involvement of $\mathrm{GAL}_{3}$ in activating neutrophils 
A

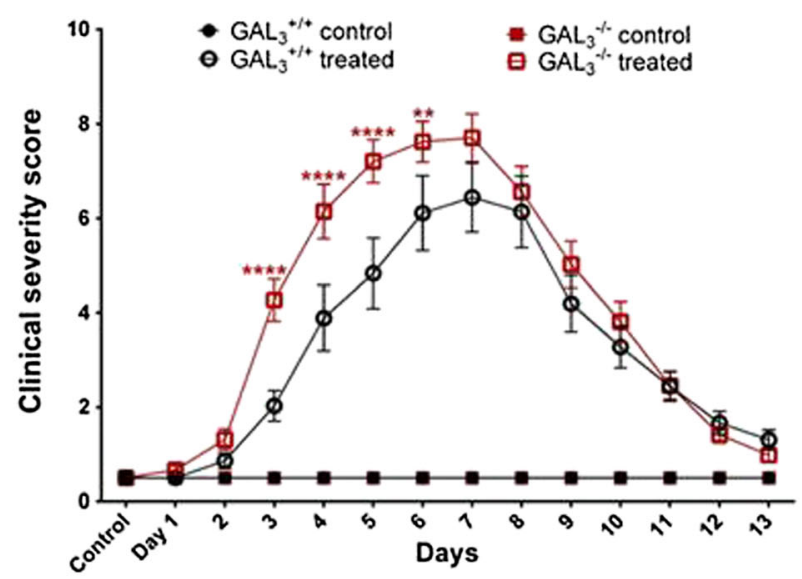

C

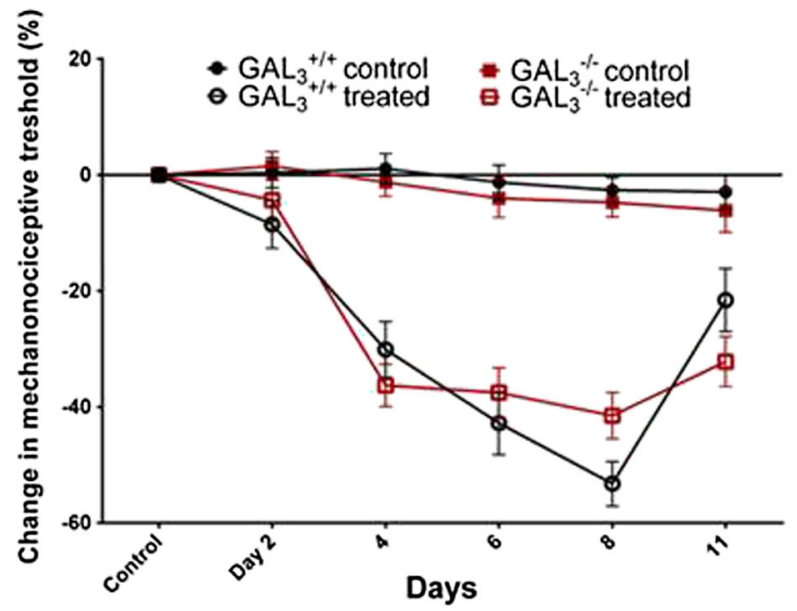

Fig. $1 \mathrm{GAL}_{3}$-deficiency leads to increased edema and inflammation without affecting nociception or motor functions. a Change of disease severity in wild-type $\left(\mathrm{GAL}_{3}{ }^{+/+}\right)$and gene-deficient $\left(\mathrm{GAL}_{3}{ }^{-/}\right)$mice. b Hindlimb edema measured by plethysmometry. c Arthritic mechanical hyperalgesia measured by plantar esthesiometry. d Motor impairment

using in vivo bioluminescence imaging. Baseline luminol bioluminescence was negligible in both groups. Following K/ $\mathrm{BxN}$ serum-transfer, the MPO-derived ROS production increased dramatically in both $\mathrm{GAL}_{3}{ }^{-/-}$and $\mathrm{GAL}_{3}{ }^{+/+}$animals, reaching a peak on day 1 . Neutrophil ROS production decreased considerably by day 5 , indicating that the disease was already in transition from a neutrophil-dominated acute phase into the chronic macrophage-mediated stage. However, MPO-activity did not differ significantly between knockouts and wild types on day 1 or 5 (Fig. 2c, d). Histological samples were harvested 14 days after serum transfer revealed a similar phenomenon. The synovial lining was thickened, and the normally adipocyte-rich periarticular connective tissue was replaced with a dense fibroblastic scar tissue, with limited inflammatory cell infiltration. No remarkable difference was
B

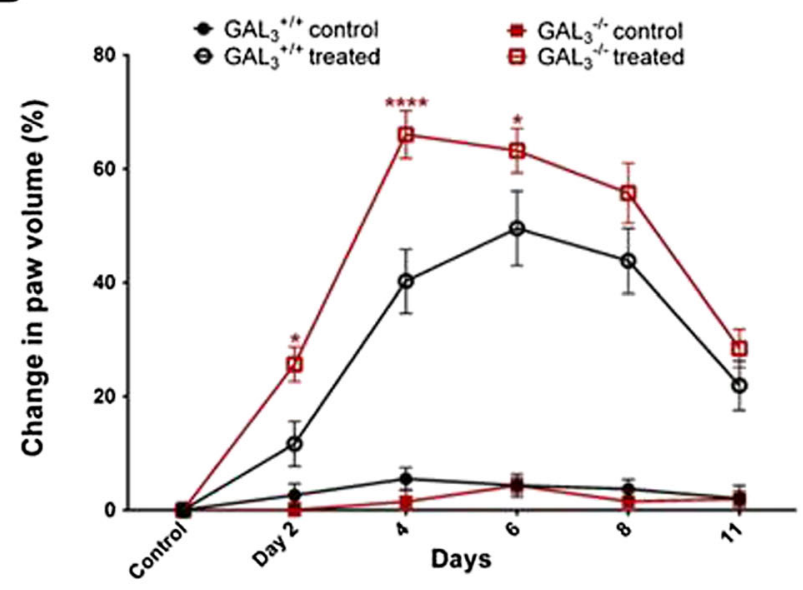

D

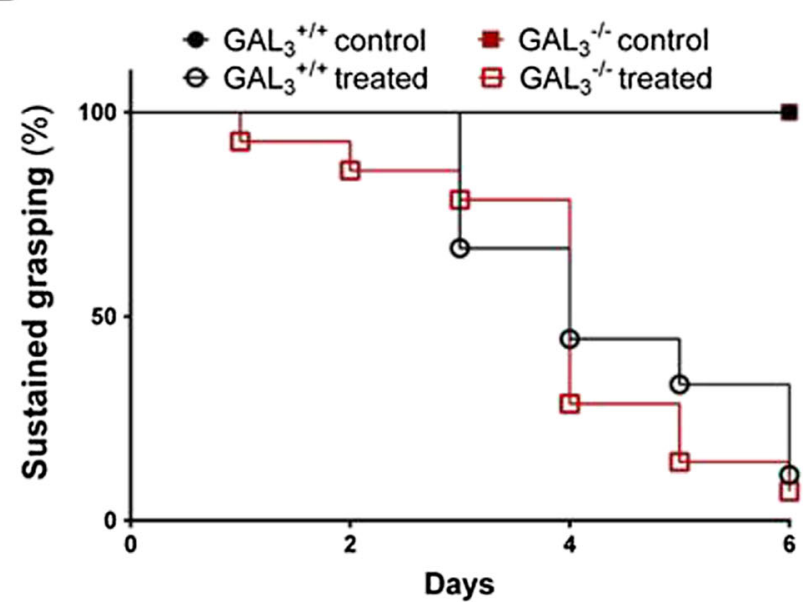

measured by wire grid grip test and plotted as a survival curve. Twoway ANOVA + Tukey's multiple comparison test, survival curve: logrank test. Controls: $n=6-7$, arthritic groups: $n=9-12 .{ }^{*} p<0.05,{ }^{* *} p<0.01$, $* * * * p<0.0001$ vs. respective wild type

observed in these respects between the study groups, in agreement with the absent functional difference at this stage of the disease (Fig. 3).

\section{Sensibilization of Neutrophils by Galanin Is $\mathrm{GAL}_{3}$ Independent}

Since no difference in neutrophil infiltration could be observed between wild-type and knockout animals, we tested if the recently reported modulation of neutrophil activation by galanin is $\mathrm{GAL}_{3}$ dependent (Locker et al. 2015). We found that in polymorphonuclear neutrophils isolated from the bone marrow (BM-PMNs) of $\mathrm{GAL}_{3}{ }^{-1-}$ mice, galanin co-treatment resulted in a similar dose- 
A

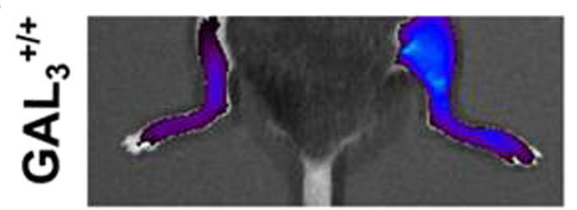

Control

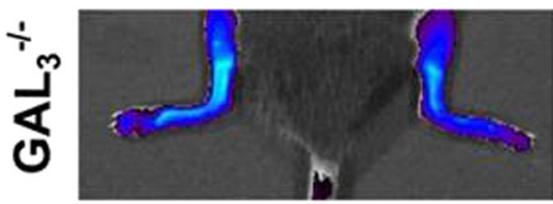

B

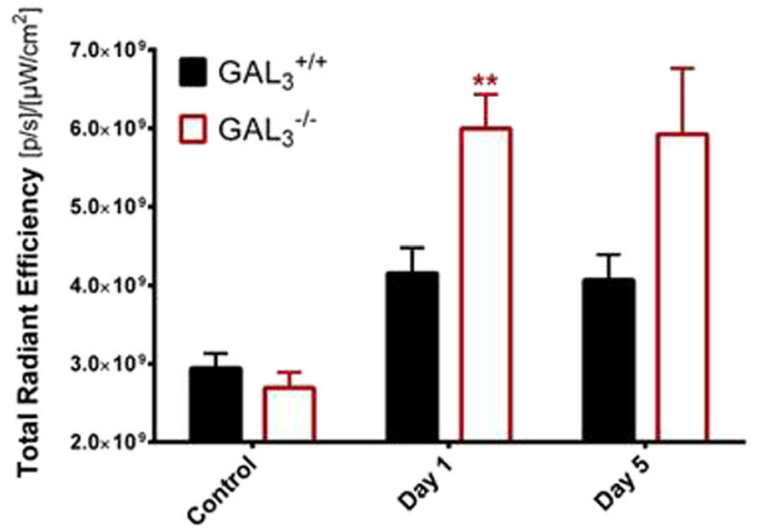

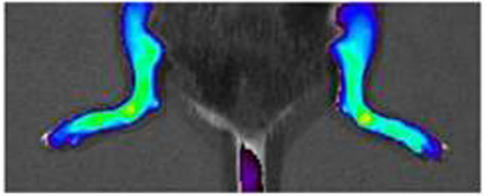

Day 1

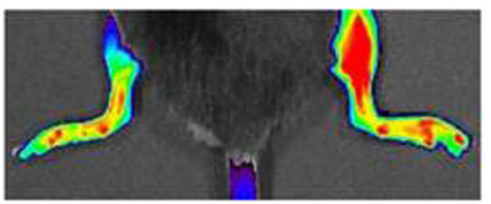

C

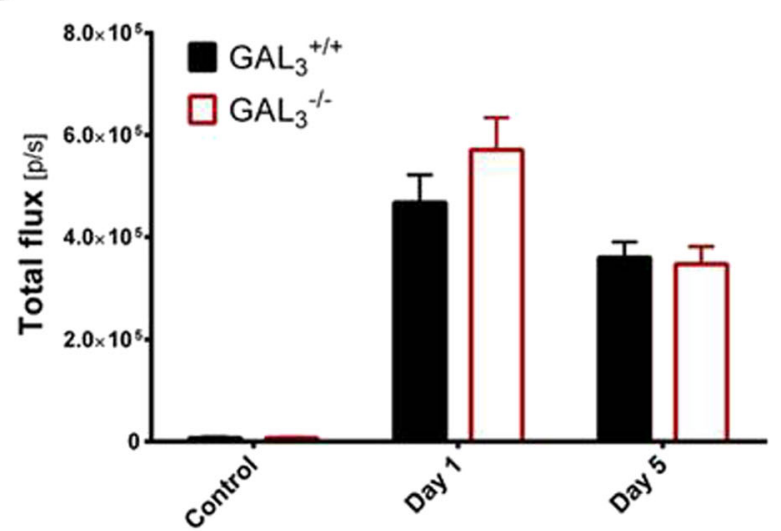

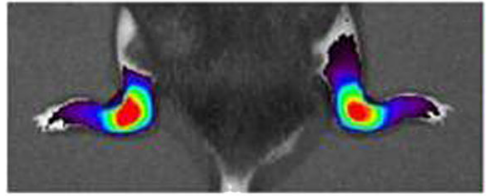

Day 5

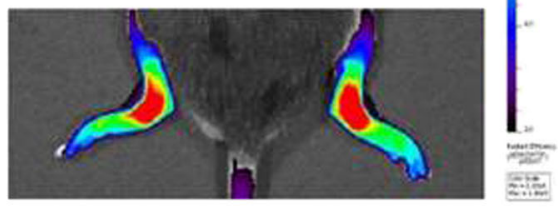

D

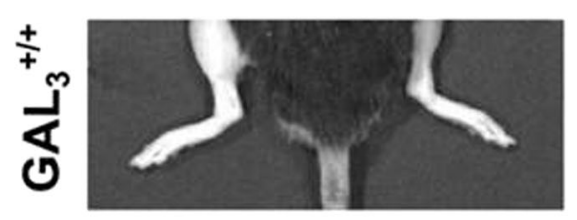

Control

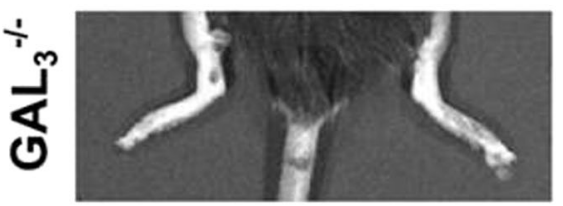

Fig. $2 \mathrm{GAL}_{3}$ deficiency results in increased and early vascular hyperpermebility in arthritis, without directly affecting neutrophil ROS production. a Representative in vivo fluorescence images highlighting indocyanine-green extravasation. b Quantification of normalized fluorescence in the hind paws representing the degree of vascular leakiness

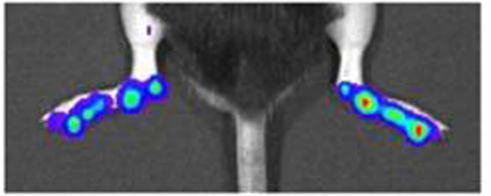

Day 1

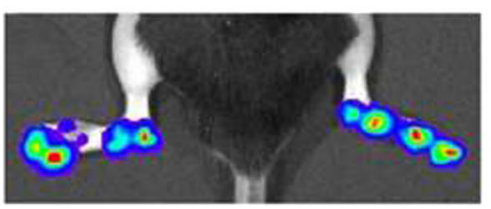

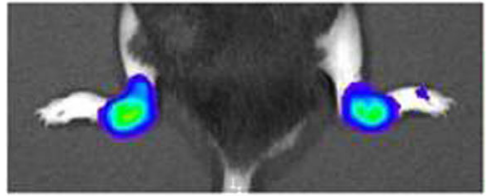

Day 5

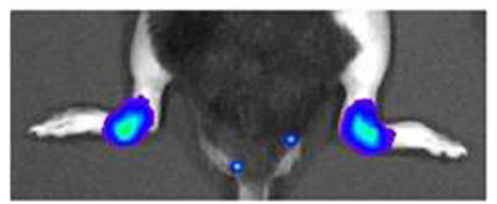

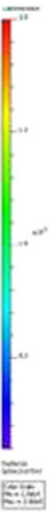

( $n=5-6)$. c Quantification of normalized luminescence in the hind limbs showing MPO-derived ROS-production of neutrophils (controls: $n=6-7$, arthritic groups: $n=9-12$ ). d Representative in vivo luminescence images. Student's unpaired $t$ test, ${ }^{* *} p<0.01$ vs. respective wild type

Expression Profiles of the Galanin System Are Not Affected by the $\mathrm{GAL}_{3}$ Knockout

Since compensatory upregulation of galanin and the other galanin receptors in the $\mathrm{GAL}_{3}{ }^{-/}$mice could potentially

dependent shift of the DMR and consequently a similar modulation of the $\mathrm{EC}_{50}$ of $\mathrm{KC}$, the murine homolog of IL-8, compared to wild-type mice (Fig. 4). This finding is in agreement with the in vivo data presented here, showing that $\mathrm{GAL}_{3}$ is not affecting neutrophil function. 

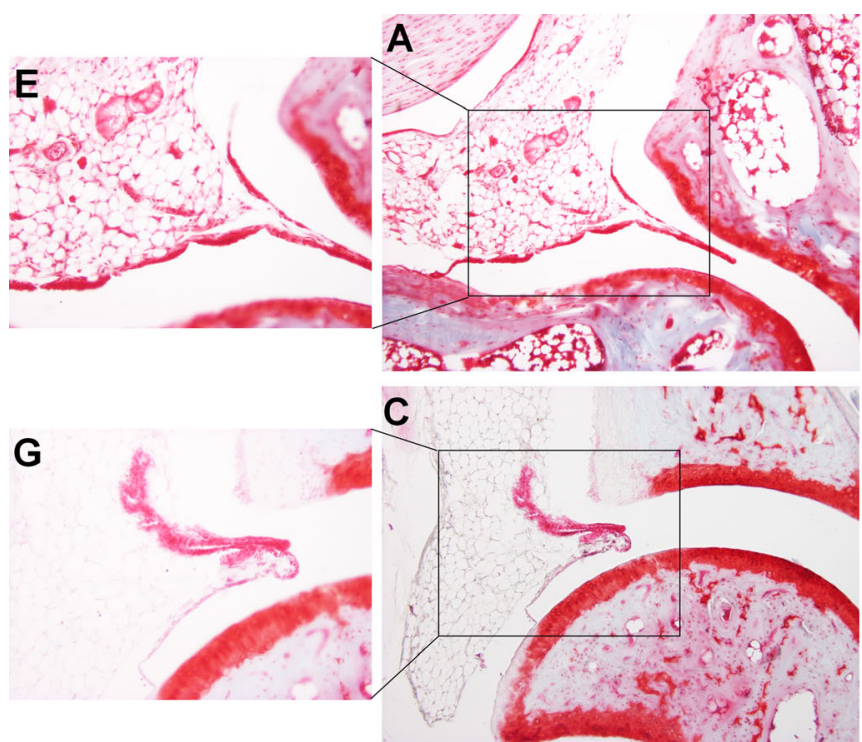

Fig. 3 Representative microphotographs of the joint samples of $\mathrm{GAL}_{3}{ }^{+/+}$ $(\mathbf{a}, \mathbf{b}, \mathbf{e}, \mathbf{f})$ and $\mathrm{GAL}_{3}{ }^{-/}(\mathbf{c}, \mathbf{d}, \mathbf{g}, \mathbf{h})$ mice taken on day 14 after arthritis induction. The adipocyte-rich periarticular connective tissue of the control groups (a, c, e, g) (illustrated by the frame) was replaced with a dense

influence our findings, we analyzed expression levels of galanin and its receptors in the spleen, lung, kidney, liver, and testes of $\mathrm{GAL}_{3}{ }^{-/-}$and $\mathrm{GAL}_{3}{ }^{+/+}$mice. We found that deltaCt values of galanin system genes compared to the housekeeping gene HPRT were similar in $\mathrm{GAL}_{3}{ }^{-/-}$and

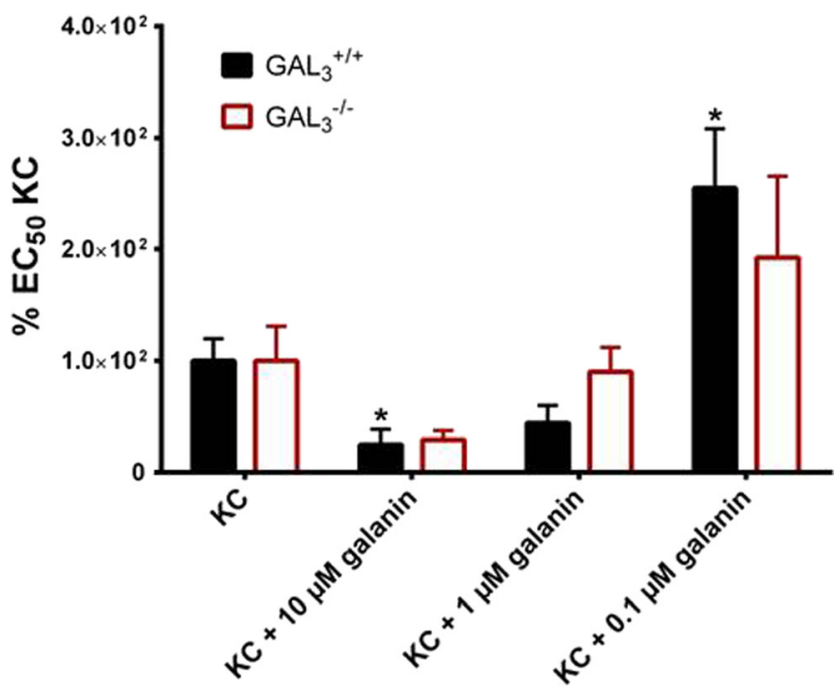

Fig. 4 Comparison of the relative $\mathrm{EC}_{50}$ of $\mathrm{BM}-\mathrm{PMNs}$ from wild-type C57BL/6 mice (Locker et al. 2015) and BM-PMNs from $G A L_{3}$ genedeficient animals. The cells were treated with $\mathrm{KC}$, the murine homo$\log$ of IL-8, in the presence of a fixed concentration of galanin. Data were normalized to $\mathrm{KC}$ treatment alone, which was set to $100 \%$. Data were analyzed with Student's $t$ test for unpaired and paired comparisons (with Welch correction), respectively. ${ }^{*} p<0.05$ vs. respective $\mathrm{KC}$ alone $(n=8-9)$

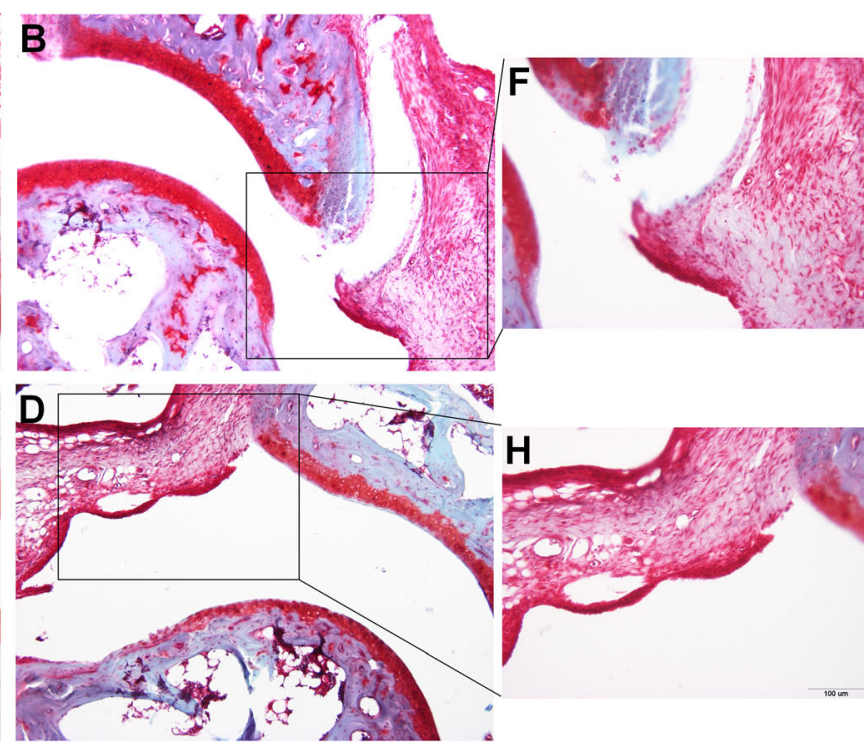

fibroblastic scar tissue, with a limited presence of inflammatory cells in the arthritic groups $(\mathbf{b}, \mathbf{d}, \mathbf{f}, \mathbf{h})$. No difference was observed in these respects between the study groups [fast green and safranin $\mathrm{O}$ staining, $\times 100(\mathbf{a}-\mathbf{d})$ and $\times 200(\mathbf{e}-\mathbf{h})$ magnification]

$\mathrm{GAL}_{3}^{+/+}$animals, indicating no compensatory mechanisms in peripheral tissues of $\mathrm{GAL}_{3}$-deficient mice (Table 1).

\section{Discussion}

Our results suggest a modest involvement of $\mathrm{GAL}_{3}$ receptor signaling in neurogenic inflammatory arthritis by decreasing microvascular leakage and consequent edema formation.

The vasoregulatory role of peripherally released galanin has been investigated previously where it was found to be able to inhibit histamine-induced edema formation in the skin (Jancso et al. 2000). Later results also revealed that $\mathrm{GAL}_{2}$ and $\mathrm{GAL}_{3}$, but not $\mathrm{GAL}_{1}$, are expressed in the skin and the anti-edema effect of galanin is presumably mediated through these receptors present on perivascular neural, but not endothelial or smooth muscle tissues (Schmidhuber et al. 2007). Consistent with our finding in $\mathrm{K} / \mathrm{BxN}$-induced arthritis, it was reported that inhibition of $\mathrm{GAL}_{3}$ signaling with SNAP 37889 also resulted in elevated edema formation (Schmidhuber et al. 2009). Our results suggest that $\mathrm{GAL}_{3}$-agonism is an endogenous protective mechanism in immune-mediated arthritis driven by neurogenic factors. Previously, it was demonstrated that galanin immunoreactivity increases in the dorsal root ganglion during experimental arthritis (Calza et al. 2000). In adjuvant arthritis of the rat, others found a decrease in galanin immunoreactivity in the sciatic nerve and macrophage-like cells, whereas it was found to be elevated, e.g., in fibroblasts, osteoblasts, and the polymorphonuclear lineage cells of the bone marrow (Qinyang et al. 2004). However, the observed 
Table 1 Expression levels of galanin system genes displayed as deltaCt values compared to the housekeeping gene $\mathrm{HPRT}_{\text {in } \mathrm{GAL}_{3}}^{+/+}$and $\mathrm{GAL}_{3}^{-/-}$ mice. Data are represented as mean \pm SEM, $n=2-4$

\begin{tabular}{|c|c|c|c|c|c|c|c|c|c|}
\hline \multirow[b]{2}{*}{ Tissue } & \multirow{2}{*}{$\begin{array}{l}\text { Gene } \\
\text { Genotype }\end{array}$} & \multicolumn{2}{|l|}{ GAL } & \multicolumn{2}{|l|}{$\mathrm{GAL}_{1}$} & \multicolumn{2}{|l|}{$\mathrm{GAL}_{2}$} & \multicolumn{2}{|l|}{$\mathrm{GAL}_{3}$} \\
\hline & & $\Delta \mathrm{Ct}$ & $p$ value & $\Delta \mathrm{Ct}$ & $p$ value & $\Delta \mathrm{Ct}$ & $p$ value & $\Delta \mathrm{Ct}$ & $p$ value \\
\hline Spleen & $\begin{array}{l}\mathrm{GAL}_{3}{ }^{+/+} \\
\mathrm{GAL}_{3}{ }^{-/-}\end{array}$ & $\begin{array}{l}4.0 \pm 1.5 \\
5.8 \pm 0.9\end{array}$ & 0.347 & $\begin{array}{l}10.0 \pm 2.1 \\
12.0 \pm 1.4\end{array}$ & 0.459 & $\begin{array}{l}14.8 \pm 0.5 \\
16.5 \pm 0.5\end{array}$ & 0.058 & $\begin{array}{l}12.0 \pm 0.5 \\
\text { n.d. }\end{array}$ & n.a. \\
\hline Lung & $\begin{array}{l}\mathrm{GAL}_{3}{ }^{+/+} \\
\mathrm{GAL}_{3}{ }^{-/-}\end{array}$ & $\begin{array}{l}5.4 \pm 0.2 \\
5.9 \pm 0.3\end{array}$ & 0.180 & $\begin{array}{l}11.3 \pm 0.8 \\
11.3 \pm 1.0\end{array}$ & 0.999 & $\begin{array}{l}12.8 \pm 0.1 \\
12.3 \pm 0.5\end{array}$ & 0.644 & $\begin{array}{l}10.3 \pm 0.5 \\
\text { n.d. }\end{array}$ & n.a. \\
\hline Kidney & $\begin{array}{l}\mathrm{GAL}_{3}{ }^{+/+} \\
\mathrm{GAL}_{3}^{-/-}\end{array}$ & $\begin{array}{l}13.2 \pm 0.4 \\
12.6 \pm 0.6\end{array}$ & 0.412 & $\begin{array}{l}14.4 \pm 1.0 \\
13.9 \pm 0.4\end{array}$ & 0.723 & $\begin{array}{l}11.1 \pm 0.3 \\
10.7 \pm 0.5\end{array}$ & 0.568 & $\begin{array}{l}9.4 \pm 0.7 \\
\text { n.d. }\end{array}$ & n.a. \\
\hline Testes & $\begin{array}{l}\mathrm{GAL}_{3}{ }^{+/+} \\
\mathrm{GAL}_{3}{ }^{-/-}\end{array}$ & $\begin{array}{l}5.5 \pm 0.5 \\
5.9 \pm 0.3\end{array}$ & 0.486 & $\begin{array}{l}\text { n.d. } \\
\text { n.d. }\end{array}$ & n.a. & $\begin{array}{l}7.5 \pm 0.4 \\
7.7 \pm 0.1\end{array}$ & 0.609 & $\begin{array}{l}13.4 \pm 0.2 \\
\text { n.d. }\end{array}$ & n.a. \\
\hline Liver & $\begin{array}{l}\mathrm{GAL}_{3}{ }^{+/+} \\
\mathrm{GAL}_{3}{ }^{-/-}\end{array}$ & $\begin{array}{l}16.7 \pm 0.9 \\
17.0 \pm 1.3\end{array}$ & 0.860 & $\begin{array}{l}\text { n.d. } \\
\text { n.d. }\end{array}$ & n.a. & $\begin{array}{l}15.2 \pm 0.6 \\
16.5 \pm 1.5\end{array}$ & 0.357 & $\begin{array}{l}15.6 \pm 0.7 \\
\text { n.d. }\end{array}$ & n.a. \\
\hline
\end{tabular}

n.d. not detectable, n.a. not applicable

difference in our model is not necessarily galanin-mediated, as galanin-like peptide (GALP) is also able to activate the $\mathrm{GAL}_{3}$ receptor (Lang et al. 2015). Furthermore, it has been shown recently that the novel neuropeptide spexin is a more potent agonist of $\mathrm{GAL}_{3}$ than galanin itself (Kim et al. 2014). Unfortunately, it has not been shown so far if spexin is able to activate $\mathrm{GAL}_{3}$ in vivo or if it is expressed in murine joints or neutrophils. Therefore, it is not possible to state which of these three peptides is responsible for the observed $\mathrm{GAL}_{3}$-mediated effects in $\mathrm{K} / \mathrm{BxN}$ induced arthritis.

We did not observe any difference in neutrophil MPO-activity, suggesting that $\mathrm{GAL}_{3}$-deficiency in vivo may not influence the function of these immune cells. Indeed, recent results show that $\mathrm{GAL}_{3}$ is not expressed in mature human blood neutrophils unlike murine bone marrow neutrophils. Whether this discrepancy reflects a species-difference or the difference between the sites of collection (peripheral blood vs. bone marrow) remains to be addressed. Galanin was also found to modulate the sensitivity of neutrophils isolated from the murine bone marrow towards $\mathrm{KC}$, the murine homolog of IL-8 (Locker et al. 2015). We show here that this modulation is independent of the $\mathrm{GAL}_{3}$ genotype, supporting the finding that neutrophil activation is not dependent on $\mathrm{GAL}_{3}$ expression, at least not in $\mathrm{K} / \mathrm{BxN}$-induced murine arthritis. Interestingly, another study found that in a mouse model of acute pancreatitis, $\mathrm{GAL}_{3}$ antagonism by the selective nonpeptide antagonist SNAP 37889 ameliorated disease severity (Barreto et al. 2011). However, more recently, SNAP 37889 has been found to be cytotoxic in a variety of cell types, including, but not limited to, myeloid lineages. Since this effect is $\mathrm{GAL}_{3}$-independent (Koller et al. 2015), results obtained with SNAP 37889 have to be interpreted with care.

The lack of effect of $G A L_{3}$ gene-deletion on mechanical hyperalgesia and accompanying loss of grasping function is supported by earlier findings implicating $\mathrm{GAL}_{1}$ and $\mathrm{GAL}_{2}$ but not $\mathrm{GAL}_{3}$ in nociceptive transmission. Since $\mathrm{GAL}_{3}$ shows only a very limited expression in the nervous system, this observation is in agreement with earlier results (Landry et al. 2005; Lang et al. 2015).

In this study, we also found no evidence that compensatory mechanisms of the galanin system occur in peripheral tissues of $\mathrm{GAL}_{3}^{-/-}$animals. Previously, Brunner and coworkers also reported no change in expression levels of the galanin system in different brain regions of these mice (Brunner et al. 2014). Therefore, compensatory mechanisms of the galanin system in $\mathrm{GAL}_{3}{ }^{-/-}$mice can be excluded. However, we did not elucidate whether expression levels of galanin signaling elements are altered in the present mouse model and which signaling pathways are involved in the observed $\mathrm{GAL}_{3}$-mediated effects. Besides, signaling properties of $\mathrm{GAL}_{3}$ are still poorly defined. One explanation for this gap in knowledge is the lack of cell lines which endogenously express $\mathrm{GAL}_{3}$ only. Additionally, overexpression of $\mathrm{GAL}_{3}$ in different cell lines leads to the translation of the protein mainly as intracellular high molecular weight protein aggregates while omitting functional activation by exogenous galanin (Robinson et al. 2013; Lang et al. 2015). In vivo, $\mathrm{GAL}_{3}$ might interact with other GPCRs or arrestins etc. which stabilize $\mathrm{GAL}_{3}$ on the membrane. However, to our knowledge, there are no data available supporting this theory.

In conclusion, our findings suggest that $\mathrm{GAL}_{3}$ is a potential target through which galanin can reduce joint swelling, but not nociception. Since the K/BxN serum-transfer model depends on an intact innervation of the hindlimb and involves early neurogenic vasodilation (Binstadt et al. 2006; Stangenberg et al. 2014), activation of the $\mathrm{GAL}_{3}$ receptor may offset and limit the extent of neurogenic inflammation in joints. However, $\mathrm{GAL}_{3}$ is not a sine qua non of the inflammatory cascade due to the functional redundancy of sensory neuropeptides on a functional level, and also because $\mathrm{GAL}_{3}$-activation is 
responsible for only a fraction of the beneficial effects of galaninergic mediators. The anti-inflammatory effect of galanin peptides is mediated via multiple receptors, and $\mathrm{GAL}_{3}$-activation does play a role in the attenuation of the vascular component of nerve-driven inflammation. Thus, affinity towards $\mathrm{GAL}_{3}$ would be a desirable attribute for the development of effective anti-edema galanin-analogs.

Acknowledgments Open access funding provided by Paracelsus Medical University. We thank Anikó Perkecz for her expert technical assistance in the histological processing and Diane Mathis and Christophe Benoist for the KRN transgene-positive mice.

Compliance with Ethical Standards All studies were approved by the Ethics Committee on Animal Research of the University of Pécs according to the Ethical Code of Animal Experiments (license no. BA $02 / 2000-2 / 2012$ ) and complied with the recommendations of the International Association for the Study of Pain.

Conflict of Interest The authors declare that they have no conflict of interest.

Funding B. Botz was supported by the TÁMOP 4.2.4. A/2-11-1-20120001 "National Excellence Program" of the European Union and the State of Hungary co-financed by the European Social Fund. The study was supported by the National Brain Research Program B (Chronic Pain Research Group; KTIA_NAP_13-2014-0022; Z. Helyes, 888819) to Z. Helyes, the Austrian Research Promotion Agency (822782/ THERAPEP), the Austrian Science Fund (P20827-B09), the European Research Council-Belgium (Starting Independent Investigator Award No. 206283 to A. Mócsai), and the Wellcome Trust-UK (International Senior Research Fellowship No. 087782 to A. Mócsai). This work is dedicated to the 650th Anniversary of the University of Pécs.

Open Access This article is distributed under the terms of the Creative Commons Attribution 4.0 International License (http:// creativecommons.org/licenses/by/4.0/), which permits unrestricted use, distribution, and reproduction in any medium, provided you give appropriate credit to the original author(s) and the source, provide a link to the Creative Commons license, and indicate if changes were made.

\section{References}

Barreto SG, Bazargan M, Zotti M, et al. (2011) Galanin receptor 3-a potential target for acute pancreatitis therapy. Neurogastroenterol Motil 23:e141-e151

Binstadt BA, Patel PR, Alencar H, et al. (2006) Particularities of the vasculature can promote the organ specificity of autoimmune attack. Nat Immunol 7:284-292

Blakeman KH, Holmberg K, Hao JX, et al. (2001) Mice over-expressing galanin have elevated heat nociceptive threshold. Neuroreport 12: 423-425

Borbely E, Botz B, Bolcskei K, et al. (2015) Capsaicin-sensitive sensory nerves exert complex regulatory functions in the serum-transfer mouse model of autoimmune arthritis. Brain Behav Immun 45:50 59

Botz B, Bolcskei K, Kereskai L, et al. (2014) Differential regulatory role of pituitary adenylate cyclase-activating polypeptide in the serumtransfer arthritis model. Arthritis Rheumatol 66:2739-2750
Bozic CR, Lu B, Hopken UE, Gerard C, Gerard NP (1996) Neurogenic amplification of immune complex inflammation. Science 273: $1722-1725$

Brogden KA, Guthmiller JM, Salzet M, Zasloff M (2005) The nervous system and innate immunity: the neuropeptide connection. Nat Immunol 6:558-564

Brunner SM, Farzi A, Locker F, et al. (2014) GAL3 receptor KO mice exhibit an anxiety-like phenotype. Proc Natl Acad Sci U S A 111: 7138-7143

Calza L, Pozza M, Arletti R, Manzini E, Hokfelt T (2000) Long-lasting regulation of galanin, opioid, and other peptides in dorsal root ganglia and spinal cord during experimental polyarthritis. Exp Neurol 164:333-343

Calza L, Pozza M, Zanni M, Manzini CU, Manzini E, Hokfelt T (1998) Peptide plasticity in primary sensory neurons and spinal cord during adjuvant-induced arthritis in the rat: an immunocytochemical and in situ hybridization study. Neuroscience 82:575-589

Ch'ng JL, Christofides ND, Anand P, et al. (1985) Distribution of galanin immunoreactivity in the central nervous system and the responses of galanin-containing neuronal pathways to injury. Neuroscience 16: 343-354

Gross S, Gammon ST, Moss BL, et al. (2009) Bioluminescence imaging of myeloperoxidase activity in vivo. Nat Med 15:455-461

Helyes Z, Szabo A, Nemeth J, et al. (2004) Antiinflammatory and analgesic effects of somatostatin released from capsaicin-sensitive sensory nerve terminals in a Freund's adjuvant-induced chronic arthritis model in the rat. Arthritis Rheum 50:1677-1685

Hokfelt T, Wiesenfeld-Hallin Z, Villar M, Melander T (1987) Increase of galanin-like immunoreactivity in rat dorsal root ganglion cells after peripheral axotomy. Neurosci Lett 83:217-220

Holmes FE, Bacon A, Pope RJ, et al. (2003) Transgenic overexpression of galanin in the dorsal root ganglia modulates pain-related behavior. Proc Natl Acad Sci U S A 100:6180-6185

Holzer P (1998) Neurogenic vasodilatation and plasma leakage in the skin. Gen Pharmacol 30:5-11

Hope PJ, Lang CW, Grubb BD, Duggan AW (1994) Release of immunoreactive galanin in the spinal cord of rats with ankle inflammation: studies with antibody microprobes. Neuroscience 60:801-807

Jakus Z, Simon E, Frommhold D, Sperandio M, Mocsai A (2009) Critical role of phospholipase Cgamma2 in integrin and $\mathrm{Fc}$ receptormediated neutrophil functions and the effector phase of autoimmune arthritis. J Exp Med 206:577-593

Jancso G, Santha P, Horvath V, Pierau F (2000) Inhibitory neurogenic modulation of histamine-induced cutaneous plasma extravasation in the pigeon. Regul Pept 95:75-80

Ji RR, Zhang X, Zhang Q, et al. (1995) Central and peripheral expression of galanin in response to inflammation. Neuroscience 68:563-576

Jones G, Halbert J, Crotty M, Shanahan EM, Batterham M, Ahern M (2003) The effect of treatment on radiological progression in rheumatoid arthritis: a systematic review of randomized placebocontrolled trials. Rheumatology (Oxford) 42:6-13

Kane D, Lockhart JC, Balint PV, Mann C, Ferrell WR, McInnes IB (2005) Protective effect of sensory denervation in inflammatory arthritis (evidence of regulatory neuroimmune pathways in the arthritic joint). Ann Rheum Dis 64:325-327

Kenne E, Lindbom L (2011) Imaging inflammatory plasma leakage in vivo. Thromb Haemost 105:783-789

Kim CW, Kim MJ, Park SB, Han SH (2012) A case of rheumatoid arthritis with unilateral knee synovial hypertrophy in hemiplegia. Ann Rehabil Med 36:144-147

Kim DK, Yun S, Son GH, et al. (2014) Coevolution of the spexin/galanin/ kisspeptin family: spexin activates galanin receptor type II and III. Endocrinology 155:1864-1873

Kioussis D, Pachnis V (2009) Immune and nervous systems: more than just a superficial similarity? Immunity $31: 705-710$ 
Kirchherr AK, Briel A, Mader K (2009) Stabilization of indocyanine green by encapsulation within micellar systems. Mol Pharm 6: 480-491

Koller A, Rid R, Beyreis M, et al. (2015) In vitro toxicity of the galanin receptor 3 antagonist SNAP 37889. Neuropeptides. doi:10.1016/j. npep.2015.12.003

Korganow AS, Ji H, Mangialaio S, et al. (1999) From systemic T cell selfreactivity to organ-specific autoimmune disease via immunoglobulins. Immunity 10:451-461

Kouskoff V, Korganow AS, Duchatelle V, Degott C, Benoist C, Mathis D (1996) Organ-specific disease provoked by systemic autoimmunity. Cell 87:811-822

Landry M, Liu HX, Shi TJ, Brumovsky P, Nagy F, Hokfelt T (2005) Galaninergic mechanisms at the spinal level: focus on histochemical phenotyping. Neuropeptides 39:223-231

Lang R, Kofler B (2011) The galanin peptide family in inflammation. Neuropeptides 45:1-8

Lang R, Gundlach AL, Holmes FE, et al. (2015) Physiology, signaling, and pharmacology of galanin peptides and receptors: three decades of emerging diversity. Pharmacol Rev 67:118-175

Levine JD, Moskowitz MA, Basbaum AI (1985) The contribution of neurogenic inflammation in experimental arthritis. J Immunol 135: $843 \mathrm{~s}-847 \mathrm{~s}$

Liu HX, Hokfelt T (2002) The participation of galanin in pain processing at the spinal level. Trends Pharmacol Sci 23:468-474

Locker F, Lang AA, Koller A, Lang R, Bianchini R, Kofler B (2015) Galanin modulates human and murine neutrophil activation in vitro. Acta Physiol (Oxf) 213:595-602

McDougall JJ, Baker CL, Hermann PM (2004) Attenuation of knee joint inflammation by peripherally administered endomorphin-1. J Mol Neurosci 22:125-137

McDougall JJ, Ferrell WR, Bray RC (1999) Neurogenic origin of articular hyperemia in early degenerative joint disease. Am J Physiol 276: R745-R752

McDougall JJ, Karimian SM, Ferrell WR (1994) Alteration of substance $\mathrm{P}$-mediated vasodilatation and sympathetic vasoconstriction in the rat knee joint by adjuvant-induced inflammation. Neurosci Lett 174: $127-129$
Mennicken F, Hoffert C, Pelletier M, Ahmad S, O’Donnell D (2002) Restricted distribution of galanin receptor 3 (GalR3) mRNA in the adult rat central nervous system. J Chem Neuroanat 24:257-268

Monach PA, Mathis D, Benoist C (2008) The K/BxN arthritis model. In: Coligan JE (ed) Current protocols in immunology, vol. 81. Greene Publishing Associates and Wiley-Interscience, New York, pp. 15.22.01-15.22.12

Qinyang W, Hultenby K, Adlan E, Lindgren JU (2004) Galanin in adjuvant arthritis in the rat. J Rheumatol 31:302-307

Robinson J, Smith A, Sturchler E, Tabrizifard S, Kamenecka T, McDonald P (2013) Development of a high-throughput screeningcompatible cell-based functional assay to identify small molecule probes of the galanin 3 receptor (GalR3). Assay Drug Dev Technol 11:468-477

Santic R, Schmidhuber SM, Lang R, et al. (2007) Alarin is a vasoactive peptide. Proc Natl Acad Sci U S A 104:10217-10222

Schmidhuber SM, Rauch I, Kofler B, Brain SD (2009) Evidence that the modulatory effect of galanin on inflammatory edema formation is mediated by the galanin receptor 3 in the murine microvasculature. $\mathrm{J}$ Mol Neurosci 37:177-181

Schmidhuber SM, Santic R, Tam CW, Bauer JW, Kofler B, Brain SD (2007) Galanin-like peptides exert potent vasoactive functions in vivo. J Invest Dermatol 127:716-721

Schmidhuber SM, Starr A, Wynick D, Kofler B, Brain SD (2008) Targeted disruption of the galanin gene attenuates inflammatory responses in murine skin. J Mol Neurosci 34:149-155

Skofitsch G, Jacobowitz DM (1985) Galanin-like immunoreactivity in capsaicin sensitive sensory neurons and ganglia. Brain Res Bull 15:191-195

Smolen JS, Aletaha D, Koeller M, Weisman MH, Emery P (2007) New therapies for treatment of rheumatoid arthritis. Lancet 370:18611874

Stangenberg L, Burzyn D, Binstadt BA, et al. (2014) Denervation protects limbs from inflammatory arthritis via an impact on the microvasculature. Proc Natl Acad Sci U S A 111:11419-11424

Thompson M, Bywaters EG (1962) Unilateral rheumatoid arthritis following hemiplegia. Ann Rheum Dis 21:370-377

Tseng JC, Kung AL (2012) In vivo imaging of inflammatory phagocytes. Chem Biol 19:1199-1209 